\title{
Investigate the Thermal Behavior of the Portable Weather Monitoring System Based on Arduino Nano
}

\author{
Ammar Yaseen Burjes ${ }^{\mathrm{a},{ }^{*}, \text { Haneafa Yahya Najm }}{ }^{\mathrm{b}}$, Ghader Salim Aziz ${ }^{\mathrm{a}}$ \\ ${ }^{a}$ Department of Physics, College of Science, University of Mosul, Iraq
${ }^{b}$ Technologies Engineering, Department of Electrical, Technical College of Mosul, Northern Technical University, Iraq \\ Corresponding email: *ammaryaseen@uomosul.edu.iq
}

\begin{abstract}
This work aims to achieve a functional system in terms of software and hardware to measure humidity with temperature and raining fall. Also, this system allows monitoring the date and time. We used Arduino Nano with the interfacing of the DHT22 sensor and a raindrop sensor placed in the local environment to measure the mentioned data. After designing the system that depends on the microcontroller Embedded on the Arduino board, we will display the data on a screen of the PC by the Arduino window (serial monitor) and display it on the LCD screen. This paper describes a simple portable design for humidity, temperature, and rain or no rain. The portable design can be made with a low cost of electronic components. It is efficiently and locally available so that it can be used to monitor weather conditions at any place. The test results showed that this system's component is small and can be packaged in a small plastic box. Besides, through the programming, we recorded the data on the Excel program, and at the same time. The data were recorded in a memory added to the manufactured system. The data obtained every five seconds are the (date, time, temperature, humidity, weather if rainy or not rainy). The system consists of two parts; the first part is inside the indoor, and it can be placed outdoor as needed and the second part is a rain sensor that can be placed outdoor. In case of rain, the buzzer and LED can be turned on to indicate the condition of rain.
\end{abstract}

Keywords - Arduino; DHT22; raindrop sensor; weather monitoring; portable; temperature.

Manuscript received 6 Jul. 2020; revised 24 Dec. 2020; accepted 20 Jan. 2021. Date of publication 30 Apr. 2021. IJASEIT is licensed under a Creative Commons Attribution-Share Alike 4.0 International License.

\section{INTRODUCTION}

Weather is the case of an atmosphere that is cold or hot, clear or cloudy, and dry or wet. Weather generally indicates the daily temperature, humidity, and precipitation activity. Weather monitoring is crucial in many applications, such as scientific systems, simulation methods, medical fields, disaster management, and agriculture [1], [2]. The large number of embedded devices that can interact with the environment is increasing significantly. It has developed microcontrollers that are easy to use and cheap that have replaced the old system that depends on complex electronic circuits [3].

The weather monitoring model continuously monitors and records atmospheric conditions via sensors. Weather is defined by the primary factors: temperature, precipitation, humidity, cloudiness, visibility, pressure, and winds. Sun is the main contributor to the constantly evolving climatic conditions. In our Solar System, energy from the sun causes many imbalances in the temperature of moving winds, which travel from place to place, causing wet, stormy, or even sunny weather. The sea plays a significant role in controlling the impact on the atmosphere. The role is caused by an immense difference in the humidity, temperature, and even pressure between the country's regions and the even coastal regions. Weather is also influenced by the inherent proportions of the earth and its rotator motion. Renewable energy (Wind and Solar) allows decentralized energy distribution, especially for meeting rural energy needs and empowering people at the grass-root level. Day-to-day weather-like everyday activity is strongly affected by weather such as agriculture, transportation, entertainment, and farming [4]. However, over the years, natural disasters have significantly impacted mankind in the form of flooding, storms, and hurricanes. In the twenty-first century, population growth, habitat destruction, deforestation, global warming, and other activities have exacerbated the impact of weather conditions on our environment. Therefore, weather monitoring stations are located around the world [5]

This sensor system informs the municipal officials of extreme traffic conditions, which can be used to alert drivers 
to hazardous situations. Thirteen examples and suggestions provided by the sensor system towards the weather are unbearable [6], [7]. An organizational multi-tied system to identify the state of the forest sector will be a socialist enterprise before the country's entrance into the capitalist age, during this age of social democracy, and post-drying, temperature, and on top of that, the fact that there would be at least, additionally, trace amounts of humidity, and pollution [8]. It is even possible that even the wind and humidity direction could affect any structure, including a greenhouse. "M02 sensor nodes" are used to acquire a specific inventive state. A web camera is also available to watch the real-time video for following up on the forest fire damage. Holding a grudge has been helpful since it easy to get and can be used to build meaningful lives. When information is received at the local site, it is in-distribution a trifling example of creative thinking the practice of using more than one communications method or approach at the same time Luminosity is currently in the process of connecting a TEM00 sensor to an Amega328 microcontroller, which is joined by a SC000 antenna with a computer chip and a SdT5 sensor, all combined into a miniature computer package with a microcontroller [9].

The text pilot SS service on the station can be used if it can be run from a cell phone. Developers of this small business environmental monitoring kit used a low-cost, distributed TIN sensor card (TN) in their designs. Data is transmitted via the protocol to both send and receive. An electronic prototype for highly automated crop condition monitoring has been created by using low-cost components and solid-state sensors. The irrigation system is intended to measure soil moisture, air, plant, and plant temperature levels in cropland [10], [11].

Weather and climate affect human activities. Human thermal comfort is largely affected by six factors: air temperature, radiation, airflow, activity level, and clothing thermal conductance, with activity coming in as a seventh [12]. Advances in technology have made these inexpensive and environmentally sensitive sensors more accessible. Sensors have been used to monitor the environment's parameters, such as temperature and humidity, for their spacebased monitoring systems[13]. These sensors have proven to be more efficient [14]. Wireless capacitive sensors [15] presented microsensor technologies for environmental monitoring using capacitive sensors. The usage of surface acoustic waves is a temperature sensor and a pressure sensor [16]. However, such systems are complicated and complex to fabricate because they utilize an integrated transmitter circuit and involve processes.

The monitoring of weather factors such as humidity, pressure, and temperature has an old history in evolution. The factors have shown clear and prominent in plant growth productivity, the efficiency of many sensitive devices for humidity with temperature, and the food industry's equality. Therefore, monitoring humidity and temperature in hospitals, halls, schools, and laboratories is very important in public health and hygiene [17]. The weather monitoring system was achieved based on Arduino Uno, DHT11 sensor, the system when tested it was able to report the weather within (20) m area [18]. It is possible to display the weather information in two ways directly and indirectly. In the direct method, LCD weather data can be shown without creating a database ground area, while indirectly, the weather information is stored in a
PC as the sensor measures climate cases [19]. The wireless weather station is designed based on the Thing Speak website, Arduino Uno, Rain sensor, DHT11, Moisture sensor, BMP180 sensor, and other pieces, the system we can use outdoor or indoors as needed. Temperature and Humidity monitoring system are designed based on DHT22, DHT11, and Arduino Uno by programming show the data in Celsius and percentage scale on LCD and also send it to Wi-Fi module which in turn sends it to Thing Speaks and then analyses the data and show it in graph form [20]. [21]. They are designed and developed wireless humidity monitors using DHT22, Arduino Uno, LCD, and RF modules used in wireless project "transmitting and receiving a radio signal." Weather detector was designed for motorcyclist drivers using Arduino, DHT22, Rain sensor, "LED was used to switch on which acts as an emergency light to another car" and GPRS/GSM module used to notify the motorcyclist by using smartphone about rain case [22]. Smart bin for the clean environment has been proposed and implemented using rain sensor, Infrared sensor, Arduino Uno, Ethernet module, Buzzer and html web page which are used to alert the authorities like a company or local waste disposal crow.

\section{Materials AND Methods}

The Arduino Nano Microcontroller board "after uploading the software" was used as the main hardware component. A raindrop sensor module is a tool for rain detection if there is any rain. The module, which is made of a rain board on which drops can be detected and a potentiometer attached to adjust the sensitivity for it with LED to show the power (on/off) for the rain alert experiment (buzzer high and LED on) a small drop of water was put on the surface of the board surface as shown on figure 1 ( $a \&$ b) (Rain or No Rain). DHT22 is an essential low-cost humidity and a temperature sensor which sensing (Temp. \& Hum.). The result data are displayed on the PC (serial monitor) and on the LCD simultaneously and record the results on the database (Excel program) and SD Card.

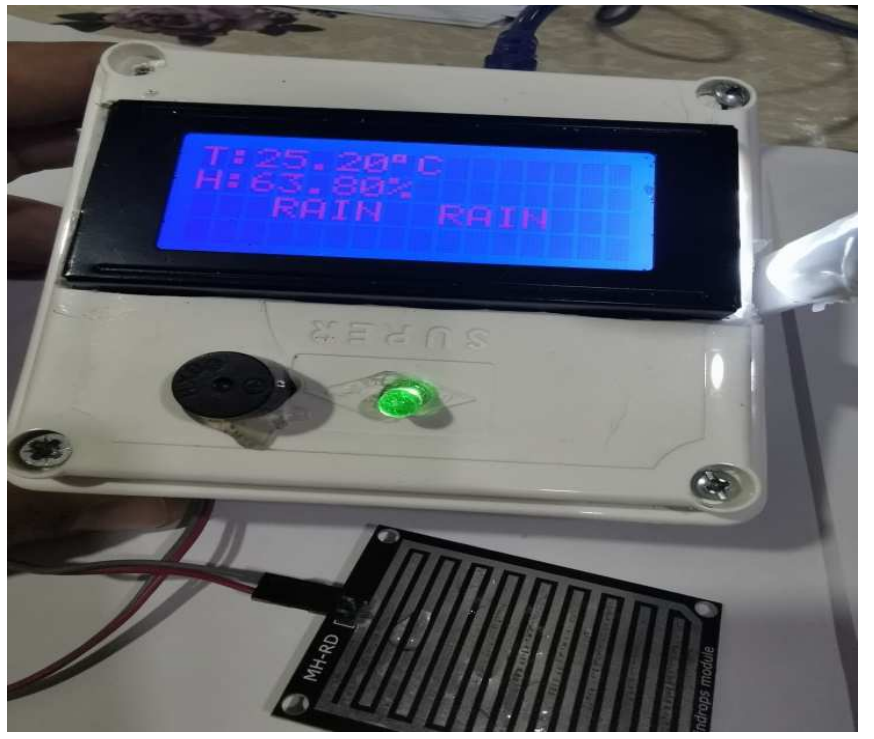

(a) 


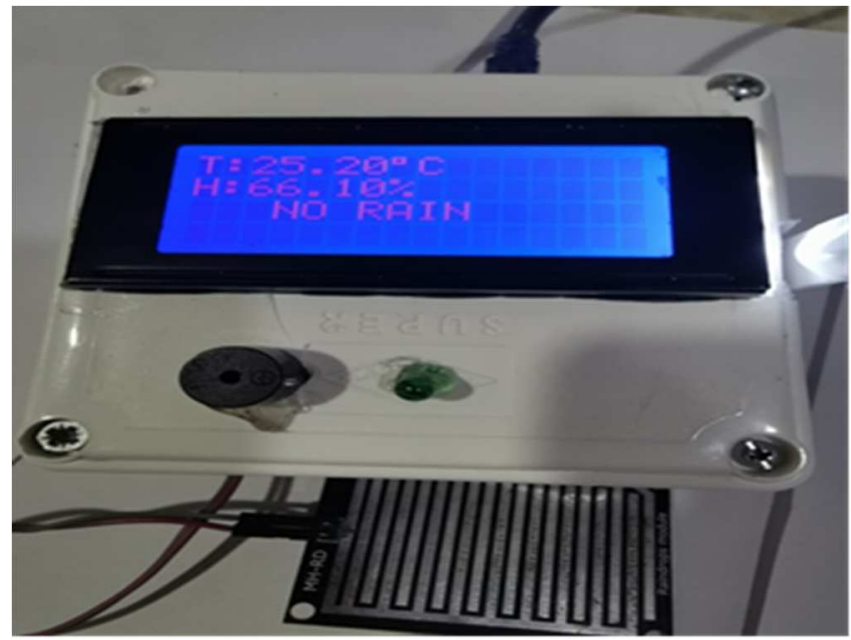

(b)

Fig. 1 Test of the System (a: in case of rain, b: No rain)

\section{A. Components Used in Project}

The system consists of two parts: hardware and software. The first hardware is shown in figure 1, which consists of some components as follows:

- Small plastic box for all components to be installed inside and on its surface.

- Medium size breadboard fixed inside a plastic box, and through which all the pieces are connected.

- Arduino Nano is the mainboard for this system, consisting of 8 analog pins and 14 digital pins; all parts must connect to the microcontroller embedded on it, then burning the program in the microcontroller.

- LCD $(20 * 4)$ with I2C module.

- The rain sensor detects the rain case and displays the data changes rain reading to the LCD.

- DHT22 sensor, detect changes humidity and temperature surrounding possesses sensitivity to temperature $\left(-40\right.$ to $\left.125^{\circ} \mathrm{C}\right)$ and humidity $(0-100 \%)$.

- SD card with external memory to records the received data.

- Buzzer and LED, for alarm with rain condition.
- Two resistors with connection wires.

- Mobile charger adapter or power bank if the system is used as a portable.

The software consists of Arduino IDE to programming all parts of work and an Excel program to show \& records the (date, rain case, Temp. and Hum. reading).

\section{B. Arduino Mega}

This board is a primary unit of control that can be programmed by a computer and designed to utilize interactive electronics in multidisciplinary projects more efficiently. This board is an open-source Microcontroller Unit (MCU) depend on ATmega 2560 with a crystal oscillator $(16 \mathrm{MHz})$. It has 15 pins that can be used as PWM outputs from 54 digital input/output pins. The board supported 16 analog inputs, a USB connection, a power jack, 4 UARTs (hardware serial ports), an ICSP header, and a reset button, the dimension (Length: $10.152 \mathrm{~cm}$, Width: $5.33 \mathrm{~cm}$, Weight: $37 \mathrm{~g}$ ). It is connected to a PC with a USB cable or power with an AC-toDC adapter or battery to get started. The Mega 2560 board is compatible with most shields designed for the Uno and some other board. All sensors will be connected to the main (MCU), which analyzes all input data and takes proper actions. Upon detecting a difference of voltage between the analog voltage sensed by the 4-LDR and the Lux sensor data, the following concatenation is conducted by the MCU.

- The MCU analyses the difference between the data obtained from the LDRs

- The MCU sends the order to the servo motor to turn them (on/off) to orient the plastic base (Fig.2) in the right direction of the enormous amount of light.

- The MCU analyses the analog received data from the Lux sensor and displays it as digital data on the LCD and PC (neither serial monitor nor record it on the Excel program with Date and the Time by programming steps).

- The MCU then stops the servo motor "once there is no longer difference of potential among the 4-LDR".

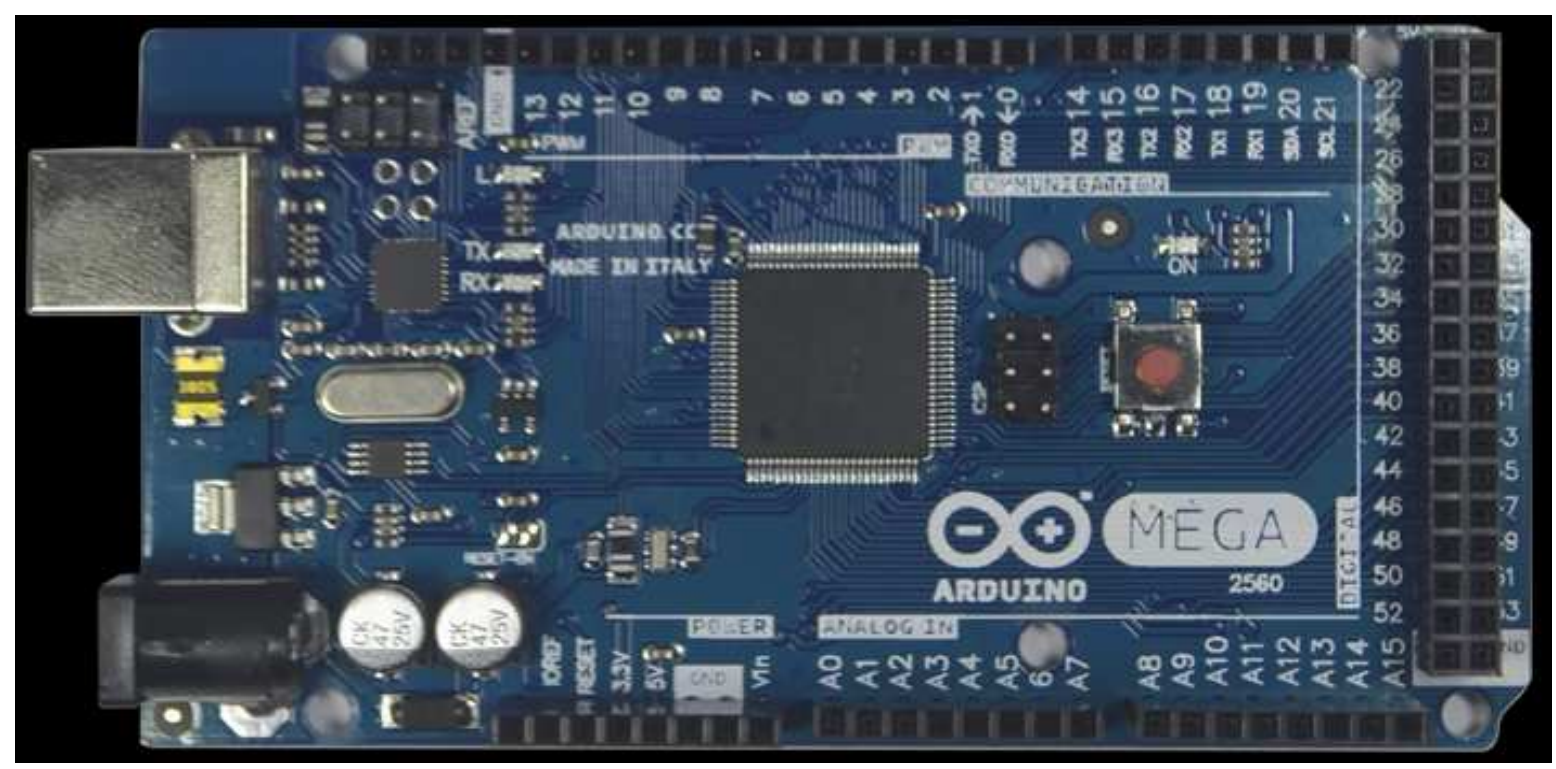

Fig. 2 Arduino Board (Mega) 


\section{Primary Boundary Conditions}

The current study's experiment has been set up based on the normal condition (outdoor temperature) where it is applied to the atmosphere and other factors, as shown in figure 3 .

Relative_Humidity
Atmospheric_Temparature
Wind_Speed
Wind_Direction
Rain_Fall
Solar_Radiation
Surface_Temperature
Ambient_Temperature

\begin{tabular}{|r|r|}
\hline \multicolumn{1}{|r|}{73.3} & Percentage \\
\hline 26.6 & Degree Celsius \\
\hline 4 & kilometers per hour \\
\hline 239 & Degrees \\
\hline 0 & milli meter \\
\hline 68 & Watts per meter square \\
\hline 28.1 & Degree Celsius \\
\cline { 1 - 1 } 26.6 & Degree Celsius
\end{tabular}

Fig. 3 Weather Measurements

\section{Sensor of rain}

Rain is liquid water formed when the vapor from the atmosphere condenses and then has been precipitated enough to fall to the ground to become liquid. A rain gauge calculates rainfall in millimeters or inches over a fixed period and records the data accordingly. A rain gauge has a funnel, two bucket units attached to form a seesaw connected. The rainwater flows into the funnel, ending up in the reservoir. The junk in the bucket can undergo various junk filtration stages before it ends up in the tipper. There are only three games of merit in which we can take part at the point of the war, and those are chess, baseball, and navigation. If much water is collected, the bucket turns to a drain. This way can enter new markets, get our message out there, and expand our companies. The second pail is now placed into the down position to catch rainwater, and rainwater from the first pail flows into the collector. At once, this device continues to operate until the bucket solenoids are placed with their magnetic reed switches near the submerged magnet, at which point the resulting pulses are produced. Water meter design Davis Instruments-7888 measures rainfall by measuring 9 $\mathrm{mm}$ per unit of precipitation produced. They arere wellinformed. Impaired drivers can constitute a greater danger than those with more than average knowledge because of their lack of driving experience. The output from the rain collector is fed to an external pin Timer. The counter timer is programmed as a plus counter.

\section{RESULTS AND DISCUSSION}

\section{A. Device Set-Up}

The microcontroller embedded in the Arduino Nano board is based on which Arduino IDE is loaded and used to develop the sketches. After that, the system can run without user intervention, "either fixed or portable." Libraries are required for this work (LCD, DHT, and SD Card), next we set up the pins of Arduino and define the variables as seen Fig. (4) "all parts needed (5V \&GND)", whereas the signal, DHT22 (D2) as INPUT,

Rain sensor (A0) as INPUT, SD Card $((11,1213,10)$ MOSI, MISO, CLK, CS respectively), LCD (SCl (A4), SDA(A5)), (Buzzer (D4), LED (D7)) as OUTPUT. Delay time as needed, the results we obtained can be viewed on a PC and LCD at the same time, besides, the data are recorded on memory and the Excel database by linking it to a program PLX-DAQ if we want to take many measurements and for a long time. The ranges of temperature and humidity are within the acceptable range for the sensor is shown in Figure 3. We also put water droplets on the rain sensor panel to show the condition reading.

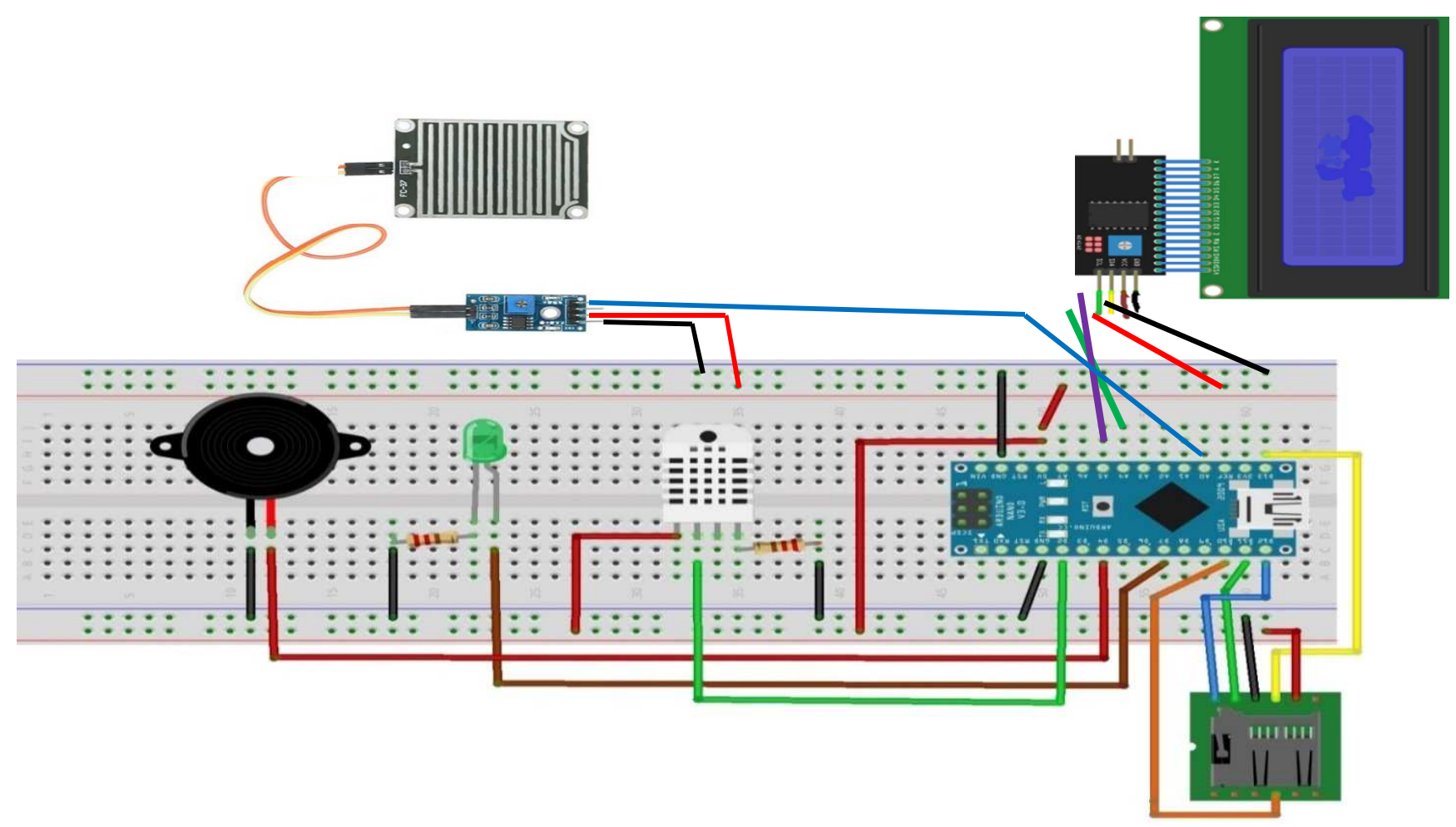

Fig. 4 The system design scheme 


\section{B. Effect of the Temperature and Relative Humidity}

Figure 5 shows the relationship between the temperature and the applied time. The results have shown that the maximum temperature happened at $3.5 \mathrm{hr}$. The min temperature happened at $5.5 \mathrm{hr}$. The extracted data showed instability in the temperature distribution. Several reasons may explain the temperature fluctuation, such as the technical conditions of the equipment itself or the weather temperature.

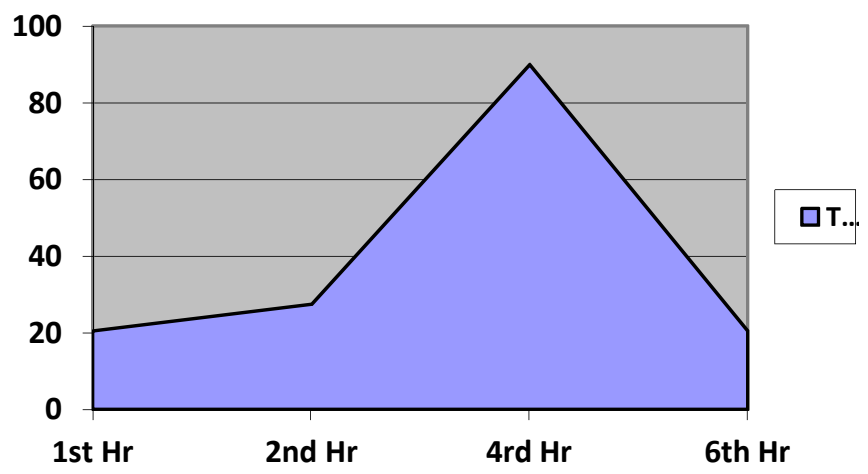

Fig. 5 Relationship between Temp and relative time

The relative humidity is the barometric coefficient of the ratio of the maximum water content of the air humidity that the air will bear to the maximum humidity the air can tolerate adherence. The standard RGB values fall into the following categories: $<20,20 \%, 20 \%$ to $40 \%, 40 \%$ to $60 \%$, and over $60 \%$ to $75 \%$. Similarly, the environmental temperature is specified as the temperature of the surrounding the earth." At different depths below the planet's surface, the temperature can be colder or hotter, with equal accuracy. The temperature is in degrees centigrade. The relative humidity results have proven that there is variety in the distribution of the weather's humidity. The results showed that the relative humidity is changeable with time, as shown the Figure 6 . where the maximum humidity is $46 \%$ at $5 \mathrm{hr}$.

\section{Humidity}

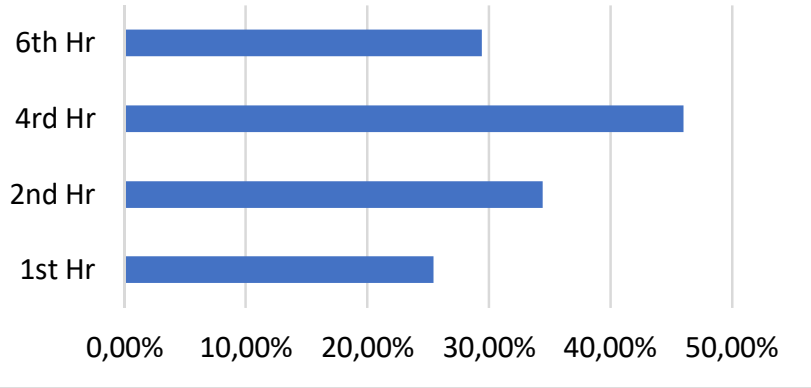

Fig. 6 Relation of the relative humidity with time

\section{CONCLUSION}

This paper describes a simple portable design for humidity, temperature, and rain or no rain. The portable can be made from a low-cost electronic component and efficiently and locally available so that it can be used to monitor weather conditions at any place in which the test is and find results, the component for this system are small, and a few that they can be packaged in a small plastic box. The project consists of two parts. The first package is made of a plastic box, which can be used to measure the humidity and temperature inside or outside as a portable device using a power bank or transformer adapter. The second part is the rain drop sensor which can be placed outside to sensify the weather's state, "rainy or no rainy" by connecting it with the system box by a wire. The project was tested several times and can be relied upon to achieve the project objective.

\section{REFERENCES}

[1] Devaraju, J. T., Suhas, K. R., Mohana, H. K., \& Patil, V. A. (2015). Wireless portable microcontroller based weather monitoring station. Measurement, 76, 189-200.

[2] Noordin, K. A., Onn, C. C., \& Ismail, M. F. (2006). A low-cost microcontroller-based weather monitoring system. $C M U$ journal, 5(1), 33-39.

[3] Rao, B. S., Rao, K. S., \& Ome, N. (2016). Internet of Things (IoT) based weather monitoring system. international journal of advanced research in computer and communication engineering, 5(9), 312-319.

[4] Jiang, P., Xia, H., He, Z., \& Wang, Z. (2009). Design of a water environment monitoring system based on wireless sensor networks. Sensors, 9(8), 6411-6434.

[5] Kulkarni, P. A., \& Vaijanath, V. Y. (2015). An economical weather monitoring system based on GSM using solar and wind energy. International Journal of Advanced Technology and Innovative Research Volume, 7, 0263-0268.

[6] Sharaf, H. K., Ishak, M. R., Sapuan, S. M., Yidris, N., \& Fattahi, A (2020). Experimental and numerical investigation of the mechanical behavior of full-scale wooden cross arm in the transmission towers in terms of load-deflection test. Journal of Materials Research and Technology, 9(4), 7937-7946.

[7] Sharaf, H. K., Ishak, M. R., Sapuan, S. M., \& Yidris, N. (2020). Conceptual design of the cross-arm for the application in the transmission towers by using TRIZ-morphological chart-ANP methods. Journal of Materials Research and Technology, 9(4), 91829188.

[8] Kumar, A., \& Hancke, G. P. (2014). Energy efficient environment monitoring system based on the IEEE 802.15. 4 standard for low cost requirements. IEEE Sensors Journal, 14(8), 2557-2566.

[9] Jiang, P., Xia, H., He, Z., \& Wang, Z. (2009). Design of a water environment monitoring system based on wireless sensor networks. Sensors, 9(8), 6411-6434.

[10] Xiao, L., \& Wang, Z. (2011). Internet of things: A new application for intelligent traffic monitoring system. Journal of networks, 6(6), 887.

[11] Sharaf, H. K., Salman, S., Dindarloo, M. H., Kondrashchenko, V. I., Davidyants, A. A., \& Kuznetsov, S. V. (2021). The effects of the viscosity and density on the natural frequency of the cylindrical nanoshells conveying viscous fluid. The European Physical Journal Plus, 136(1), 1-19.

[12] Sarkar, I., Pal, B., Datta, A., \& Roy, S. (2019). Wi-Fi-Based Portable Weather Station for Monitoring Temperature, Relative Humidity, Pressure, Precipitation, Wind. Information and Communication Technology for Sustainable Development: Proceedings of ICT4SD 2018, 933, 399 .

[13] Benghanem, M. (2009). Measurement of meteorological data based on wireless data acquisition system monitoring. Applied energy, 86(12), 2651-2660.

[14] Sharaf, H. K., Salman, S., Abdulateef, M. H., Magizov, R. R., Troitskii, V. I., Mahmoud, Z. H., ... \& Mohanty, H. (2021). Role of initial stored energy on hydrogen microalloying of $\mathrm{ZrCoAl}(\mathrm{Nb})$ bulk metallic glasses. Applied Physics A, 127(1), 1-7.

[15] N Genikomsakis, K., Galatoulas, N. F., I Dallas, P., Candanedo Ibarra, L. M., Margaritis, D., \& S Ioakimidis, C. (2018). Development and on-field testing of low-cost portable system for monitoring PM2. 5 concentrations. Sensors, 18(4), 1056.

[16] Martín-Garín, A., Millán-García, J. A., Baïri, A., Millán-Medel, J., \& Sala-Lizarraga, J. M. (2018). Environmental monitoring system based on an Open Source Platform and the Internet of Things for a building energy retrofit. Automation in Construction, 87, 201-214.

[17] Yunus, N. A. M., Zainudin, M. A., Sulaiman, N., \& Abbas, Z. A (2018, November). Microfluidic Fluid Flow Design with Arduino Relay and Temperature Controller for Processor. In 2018 IEEE 5th International Conference on Smart Instrumentation, Measurement and Application (ICSIMA) (pp. 1-4). IEEE. 
[18] Waaiz, M., Reddy, K. K., \& Punyaseshudu, D. (2017). Design and Development of Portable Automatic Weather System. International Journal of Applied Environmental Sciences, 12(2), 383-398.

[19] Gunawan, T. S., Munir, Y. M. S., Kartiwi, M., \& Mansor, H. (2018) Design and implementation of portable outdoor air quality measurement systemn using arduino. International Journal of Electrical and Computer Engineering, 8(1), 280.

[20] Ni, Y. Q., Xia, Y., Liao, W. Y., \& Ko, J. M. (2009). Technology innovation in developing the structural health monitoring system for Guangzhou New TV Tower. Structural Control and Health Monitoring: The Official Journal of the International Association for
Structural Control and Monitoring and of the European Association for the Control of Structures, 16(1), 73-98.

[21] Al-Kuwari, M., Ramadan, A., Ismael, Y., Al-Sughair, L., Gastli, A., \& Benammar, M. (2018, April). Smart-home automation using IoTbased sensing and monitoring platform. In 2018 IEEE 12th International Conference on Compatibility, Power Electronics and Power Engineering (CPE-POWERENG 2018) (pp. 1-6). IEEE

[22] Khandakar, A., Chowdhury, M. E., Ahmed, R., Dhib, A., Mohammed, M., Al-Emadi, N. A., \& Michelson, D. (2019). Portable system for monitoring and controlling driver behavior and the use of a mobile phone while driving. Sensors, 19(7), 1563.. 